\title{
ESPORTE E LAZER EM COMUNIDADES QUILOMBOLAS NO PARANÁ: IDENTIFICANDO REALIDADES E APONTANDO DESAFIOS PARA IMPLEMENTAÇÃO E/OU APRIMORAMENTO DE POLÍTICAS PỦBLICAS ${ }^{1}$
}

\author{
Larissa Michelle Lara \\ Universidade Estadual de Maringá, Maringá, Paraná, Brasill
}

\section{Resumo:}

Esse texto trata da investigação do esporte e lazer em comunidades quilombolas no estado do Paraná com o objetivo de identificar carências e avaliar as condições específicas para implementação e/ou aprimoramento de políticas públicas de esporte e lazer, em interlocução com outras esferas sociais. O mapeamento da realidade quilombola no Estado poderá servir de referencial para ações de intervenção que venham a considerar esporte e lazer como direitos constitucionais a serem materializados nessas localidades.

Palavras-chave: Políticas Públicas. Esporte. Lazer.

\section{Introdução}

De que vale seu cabelo liso e as ideias enroladas

Dentro da sua cabeça

Ana Carolina ${ }^{2}$

\begin{abstract}
$\mathrm{O}$ tema das comunidades quilombolas tem sido corrente no debate acadêmico atual sobre diferentes campos do conhecimento e passa a ser intensamente demarcado na história dos movimentos sociais no Brasil. As tentativas conceituais de captar o fenômeno são diversas e englobam finalidades acadêmica, governamental e/ou de ações de

1-Essa pesquisa não poderia ter sido desenvolvida sem o apoio direto da maioria dos membros do Grupo de Pesquisa Corpo, Cultura e Ludicidade, vinculado ao Laboratório de Estudos da Cultura junto ao Programa de Pós-Graduação Associado em Educação Física UEM-UEL.
\end{abstract}

2-CAROLINA, A. Implicante. Letra de Música. Disponível em: http://ana-carolina.musicas.mus.br/letras/74517. Acesso em: 25 nov. 2011. 
luta e resistência. $\mathrm{O}$ entendimento de comunidades quilombolas passa pelo debate acerca do que seja negro, diáspora, afro-brasileiro, racismo, remanescente, ancestralidade, entre outros termos de difícil definição. Daí que assumir um conceito sobre o que seriam comunidades quilombolas em meio ao mosaico de representações é correr o risco de torná-lo limitado. Assim, a observância à flexibilidade de olhares a partir das teorias constitutivas desse tema é necessária, reconhecendo elementos consensuais mínimos que favoreçam a problematização temática.

Com base nessa orientação, as comunidades quilombolas passam a ser percebidas e explicitadas nesse texto como aquelas que, embora não possuam idênticos modos de vida, organizam-se em torno do eixo central que é a terra, não apenas como condição material para plantar, colher e promover a subsistência, mas como modo existencial de sua cidadania, pertencimento, relações familiares/sociais e reposição de energias laborais. Assim, fazemos menção às comunidades quilombolas como aquelas que congregam laços de convivência e coletividade, tomando a terra como centralidade de suas lutas em decorrência do processo de exclusão e marginalidade que seus ancestrais sofreram no contexto escravagista brasileiro. Tais comunidades ainda enfrentam uma série de percalços, a exemplo da grilagem de terra, da falta de apoio do governo e da escassez de condições de trabalho, saúde, educação, lazer, esporte, e se organizam a partir da reivindicação de seus direitos e de sua cidadania.

A tematização das comunidades quilombolas no campo da Educação Física ainda é uma ação recente, carecendo de interlocutores que possam debater o tema, problematizá-lo e legitimá-lo junto à área. No campo investigativo, o Grupo de Pesquisa Corpo, Cultura e Ludicidade (GPCCL), da Universidade Estadual de Maringá, vem, desde 2008, desenvolvendo estudos junto a essas comunidades no Paraná com o objetivo de mapear as políticas públicas de esporte e lazer e identificar suas práticas corporais, com estruturação e deflagração de ações que viessem a somar esforços na melhoria das condições esportivas e de lazer dessas comunidades ${ }^{3}$.

3-A realização do Seminário de Cultura Corporal Afro-Brasileira, em 2010, na Universidade Estadual de Maringá, e o I Seminário de Estudos Quilombolas, em 2011, na Universidade Federal de Goiás, ambos com participação de membros de comunidades quilombolas, representam ações relevantes ao processo de legitimação desse campo investigativo na área da Educação Física. Vale destacar também 
O recorte extraído para esse texto foca a investigação do esporte e lazer em comunidades quilombolas no Paraná com o objetivo de identificar carências e avaliar as condições específicas para implementação e/ou aprimoramento de políticas públicas de esporte e lazer, em interlocução com outras esferas sociais. Partimos do entendimento de que as políticas públicas, visualizadas aqui como ações implementadas pelos governos federal, estadual e/ou municipal (articuladas a diferentes setores de intervenção) em atendimento às carências e demandas populacionais, podem se constituir, dependendo da forma como forem construídas, em um dos mecanismos de luta por condições materiais, simbólicas e existenciais dessas comunidades.

\section{A imersão em comunidades quilombolas: descortinar e construir}

A pesquisa desenvolvida em comunidades quilombolas no Paraná, financiada de 2008 a 2009 pela Rede Cedes/Secretaria Nacional de Desenvolvimento de Esporte e de Lazer/Ministério do Esporte e, de 2010 a 2011, pela Fundação Araucária, tem seu mérito ressaltado em apontamento feito por Silva (2010, p. 7) ao esclarecer que, no sul do Brasil e, notadamente no Paraná, ideias de uma formação unicamente europeia ainda integram "parte da constituição de imaginário racista", que tem por base as 'políticas de branqueamento' do século XIX. Daí que trazer à tona a realidade de comunidades quilombolas nesse estado é contribuir para desmistificar esse imaginário social marcado por preconceitos e distorções.

Partindo do mapeamento elaborado pelo Grupo de Trabalho Clóvis Moura $^{4}$, com apoio do Instituto de Terras, Cartografia e Geociências

as investigações desenvolvidas por pesquisadores junto ao Labphysis - Laboratório Physis de Pesquisa em Educação Física, Corpo e Natureza, da Faculdade de Educação Física da Universidade Federal de Goiás (cf. SILVA, A. M.; FALCÃO, J.L.C. (orgs.) Práticas corporais em comunidades quilombolas de Goiás. Goiânia: Ed. Da PUC Goiás, 2011) e também pelo Grupo de Estudos e Pesquisas em Educação e Saúde das Populações Amazônicas (GEPESPA), da Universidade Estadual do Pará.

4-O Grupo de Trabalho Clóvis Moura, ligado ao Governo do Estado, tem esse nome em homenagem ao intelectual, pesquisador, historiador e militante do movimento negro, falecido em 2003. Cf. informações sobre as comunidades quilombolas em: PARANÁ. Grupo de Trabalho Clóvis Moura. Disponível em: http://www.quilombos.pr.gov.br. Acesso em: 11 set. 2011.

Pensar a Prática, Goiânia, v. 15, n. 1, p. 1-271, jan./mar. 2012 
(ITCG), observamos três classificações para as comunidades encontradas no Paraná: a) comunidades remanescentes de quilombo; b) comunidades negras tradicionais; c) indicativos de comunidades quilombolas. No momento de estruturação da pesquisa, em 2007, 30 eram as comunidades remanescentes de quilombo no Paraná 5 , sendo 27 delas pesquisadas entre 2008 e 2009 . Dessas, quatro foram eleitas no intuito de intensificar a coleta dos dados e, efetivamente, traçar estratégias que pudessem contribuir com a vida desses atores sociais em termos de esporte e lazer.

O critério de seleção das comunidades baseou-se naquelas que mais chamaram atenção dos pesquisadores em pesquisa anterior, nos anos de 2008 a 2009, e que mereciam continuidade investigativa. Assim, fez-se opção por um quilombo que contasse com um programa de política pública (Feixo, na Lapa); um que tivesse traços de etnia africana (Manoel Ciriaco dos Santos, em Guaíra); um em que as práticas corporais afro-brasileiras tivessem ressonância na comunidade e fora dela (Paiol de Telha, em Guarapuava); e outro carente em termos de condições materiais para sua sobrevivência, tendo a religião como elemento central de seu cotidiano (Córrego do Franco, em Adrianópolis). $\mathrm{O}$ intuito era o retorno a essas comunidades para trabalhar com as lideranças e os atores sociais por meio de dinâmicas de grupo que os levassem à discussão de seus problemas e a avaliar seus interesses por políticas públicas de esporte e lazer.

Cinco fases compuseram o desenvolvimento do projeto, no período de 2010 a 2011, envolvendo a participação de 17 pesquisadores, entre acadêmicos de graduação, pós-graduação e professores integrantes do Grupo de Pesquisa Corpo, Cultura e Ludicidade. A dinâmica de trabalho agregou encontros preparatórios para a inserção em campo no sentido de capacitar adequadamente os pesquisadores, leituras e estudos em grupo, ingresso dos pesquisadores em campo por 25 dias, organização e análise de todo o material coletado, estruturação e disseminação da produção acadêmico-científica, com observações participantes, entrevistas, análise de documentos disponibilizados pelos quilombolas, filmagens e fotografias no sentido de complementação das obser-

5-Ao final de 2007, a Fundação Cultural Palmares, vinculada ao Ministério da Cultura, certificou 34 comunidades, número mantido em 2011. Cf. BRASIL. Fundação Cultural Palmares. Disponível em: http://www.quilombos.pr.gov.br. Acesso em: 11 set. 2011.

Pensar a Prática, Goiânia, v. 15, n. 1, p. 1-271, jan./mar. 2012 
vações obtidas. Os dados coletados foram transcritos em diário de campo e analisados a partir de orientações próprias do estudo do tipo etnográfico.

\section{Sobre as comunidades quilombolas investigadas}

A imersão em campo foi crucial para o entendimento de como seria uma comunidade quilombola, pois, inicialmente, partimos da ideia de que os quilombolas realizavam, ainda, suas práticas corporais afrobrasileiras e que os quilombos eram constituídos, em grande parte, por negros. Entretanto, a diversidade do campo mostrou que várias configurações são possíveis e que estar atento aos modos distintos de organização dos quilombos é um passo essencial para o reconhecimento dessas comunidades, na forma como realmente são. Como lembra Arruti $(2009$, p. 78$)$, há “[...] importantes variações sociais na organização da unidade familiar quilombola", o que nos leva a perceber esse campo em suas aproximações e distanciamentos. Assim, reconhecer essas comunidades é uma forma de ingressar em suas especificidades e nas características que as tornam singulares e, ao mesmo tempo, únicas, identificando modos próprios que orientem ações em termos de políticas públicas.

A comunidade quilombola do Feixo localiza-se no município da Lapa, distante a $18 \mathrm{~km}$ do centro da cidade e a $70 \mathrm{~km}$ de Curitiba, no Paraná. O modo de vida dessa comunidade resume-se a trabalho doméstico e rural no período da colheita. A comunidade sobrevive ainda de subempregos na Vila Mariental - a comunidade alemã -, e também de poucos empregos na Granja ou na Indústria Química. Moram no local, aproximadamente, 1.200 pessoas, porém, nem todas são quilombolas. Não há creche ou centro de Educação Infantil no quilombo, mas apenas uma escola municipal de $1^{\mathrm{a}}$ a $4^{\mathrm{a}}$ série.

Para os jovens, a diversão se materializa na forma de danças, sendo funk e vanerão os ritmos predominantes na região. As crianças soltam pipa, nadam nos rios, brincam de boneca, carrinho, interagem com a natureza e os animais. O esporte realizado na comunidade é o futebol, exclusivamente como prática masculina. A Igreja se encarrega de parte do lazer dos moradores por meio das festas de louvor aos santos, das procissões e dos bingos. Alguns mantêm a tradição dos benzimentos, do uso dos banhos de ervas e chá para a cura de enfermidade, embora não sejam presentes práticas de religião afro-brasileira. 
Desde 2008, as famílias recebem o Programa Segundo Tempo (PST), que objetiva democratizar o acesso à prática e à cultura do esporte, prioritariamente em áreas de vulnerabilidade social. Esse Programa, no Feixo, tem como atividades desenvolvidas: futebol, voleibol, dança, capoeira, artes e ginástica, as quais despertam interesse das crianças, embora tratadas de modo desvinculado das relações históricas e culturais do negro.

A comunidade quilombola Manoel Ciriaco dos Santos localiza-se a 20 km do município de Guaíra - PR e encontra-se próxima ao vilarejo Maracaju dos Gaúchos, formado por uma colônia de italianos. Atualmente, vivem nessa localidade sete famílias, constituídas de 57 pessoas. Como atividade geradora de renda, a comunidade se dedica à produção e venda de hortifrutigranjeiros para os restaurantes do município de Guaíra. O trabalho campesino sempre foi a principal ocupação dos moradores da comunidade quilombola e sua fonte de renda primordial advém de atividades laborais em lavouras vizinhas.

A Educação Infantil, as séries iniciais do Ensino Fundamental e a Educação de Jovens e Adultos são oferecidas em uma escola municipal na Vila Maracaju dos Gaúchos, que trabalha com salas multisseriadas. Na comunidade, as mulheres são responsáveis pelos trabalhos domésticos e cuidados com os filhos. As crianças ocupam seu tempo nadando no lago, brincando de futebol, de jogos virtuais, soltando pipas, andando de bicicleta e pescando. Os adultos ouvem vanerão, funk, sertanejo e axé, confraternizam-se com vizinhos, vão a bailes no município de Terra Roxa e nas casas de amigos. A prática da capoeira, presente no quilombo, representa muito para a comunidade, sobretudo por lembrar suas disputas territoriais, que são intensas.

A comunidade quilombola de Córrego do Franco localiza-se no município de Adrianópolis-PR, na divisa com o estado de São Paulo, a $9 \mathrm{~km}$ do município de Barra do Turvo-SP, e está afetada pelo isolamento dentro da unidade federativa a qual pertence, dificultando o acesso aos serviços públicos estaduais. Atualmente, 75 famílias habitam a comunidade e 35 são consideradas quilombolas. Suas principais reivindicações são melhorias na saúde, no trabalho, na educação e ponte sólida ou balsa para a travessia do rio, de modo a facilitar a locomoção das famílias e a entrada de veículos e produtos.

Os trabalhos ocorrem por meio de empreitadas em fazendas vizinhas, com extração de leite, plantação de culturas, criação de animais, capinagem, assim como na agricultura familiar e em atividades na ci- 
dade. De $1^{\mathrm{a}}$ a $4^{\mathrm{a}}$ série há escola na própria comunidade com uma sala para atender a quatro séries simultaneamente e um pequeno parque no quintal com alguns brinquedos. A maioria dos jovens, com a conclusão do Ensino Fundamental ou Médio, muda-se para cidades vizinhas em busca de empregos.

A religião predominante é a protestante, representada por três igrejas: a Assembleia de Deus, a Congregação Cristã do Brasil e a Igreja Redenção, as quais têm grande influência no cotidiano dos moradores, tanto que nenhuma manifestação da cultura afro-brasileira foi encontrada nessa comunidade. Nela, não existe nenhum espaço específico de lazer proporcionado por algum órgão público. Porém, há recursos naturais do próprio local que propiciam aos moradores nadarem nos rios e cachoeiras dos arredores. Há também um campo de futebol que é utilizado como distração para os mais jovens e para treino de um time da localidade.

A comunidade quilombola Invernada Paiol de Telha possui quatro núcleos, denominados como: Núcleo Barranco, Núcleo Pinhão, Núcleo Assentamento e Núcleo Guarapuava. Entretanto, para essa pesquisa, foi considerado apenas o Núcleo Assentamento, formado por 26 famílias descendentes de negros e aproximadamente 30 famílias sem terras, assentadas pelo INCRA, localizado a $35 \mathrm{~km}$ da cidade de Guarapuava, possuindo reserva com rios e cachoeiras, minas preservadas e animais nativos. A estrutura de trabalho da comunidade baseia-se na agricultura familiar, na criação de gado leiteiro, horta comunitária, produção de pães, bolachas e queijos caseiros. Muitos também possuem empregos na cidade de Guarapuava ou nas colônias vizinhas.

Dado o fato de a comunidade de quilombolas do assentamento ser formada por católicos, protestantes e membros do candomblé, o convívio não é pacífico. A Cia. de Música e Dança Afro Kundun Balê, formada por quilombolas do Paiol de Telha, participa efetivamente do culto aos orixás do candomblé e contribui com ações interventoras no intuito de auxiliar a comunidade em suas lutas e no desenvolvimento e disseminação da cultura afro-brasileira.

A comunidade do Núcleo Assentamento realiza reuniões no Barracão da Associação, festas (como as juninas ou datas festivas) e atividades que visam ajudar financeiramente alguma família. $\mathrm{Na}$ comunidade, há um campo de futebol, frequentado por adolescentes e adultos nos finais de semana e por crianças que nesse local gostam de se reunir para jogar e brincar. 
Com os apontamos realizados acerca dessas comunidades, embora sinteticamente organizados nesse texto, é possível fazer um exercício de síntese no sentido propositivo. A observação das realidades quilombolas investigadas torna visível a existência de apenas uma política pública de esporte e lazer na comunidade quilombola do Feixo, a qual entende que a política do Programa Segundo Tempo precisa ser continuada e que a implementação de outras políticas públicas é bem vinda, aliada a necessidades como segurança, alimentação e transporte. Contrariamente, as demais comunidades não têm implantada nenhuma política pública de esporte e lazer. Os moradores possuem lazer, embora nem sempre o reconheçam, e mostram-se receptivos à realização de atividades esportivas e recreativas, sobretudo aquelas que possam considerar os problemas emergentes nas localidades e as diferenças dos grupos sociais. Essa ideia é referendada por parte significativa dos integrantes das comunidades, os quais entendem que o esporte e o lazer podem contribuir de forma efetiva em suas relações cotidianas, como mais um elemento para que eles sejam ouvidos em suas reivindicações e lutas. Entretanto, como observado, esporte e lazer não são considerados, para eles, necessidades básicas, o que exige esforços no sentido de intensificar esse debate na coletividade.

\section{A realidade do esporte e lazer em comunidades quilombolas e os desafios de uma ação interventora}

A pesquisa possibilitou-nos refinar o olhar para um tema complexo e que se refere às condições de esporte e lazer, práticas nem sempre visualizadas como importantes em meio a inúmeras carências que afetam o cotidiano das comunidades quilombolas. Trazer esse tema junto aos comunitários foi possibilitar reflexões acerca da hierarquia das necessidades $^{6}$, levando-os a perceber que simultaneamente à luta pelo direito à terra, outros direitos podem ser conquistados, como o direito constitucional ao esporte e ao lazer (BRASIL, 1988). Isso porque, de

6-A teoria do psicólogo americano Abraham Maslow foca uma escala piramidal das necessidades, que tem na base a necessidade fisiológica (comida, sexo, sono, excreção), seguido de segurança (emprego, saúde, família, recursos financeiros), amor/relacionamento, autoestima, até chegar ao topo com a realização pessoal (moralidade, criatividade, ausência de preconceito). Para ele, enquanto não satisfeitas as necessidades de base (nível baixo), outras de nível alto não podem ser supridas.

Pensar a Prática, Goiânia, v. 15, n. 1, p. 1-271, jan./mar. 2012 
modo geral, as comunidades investigadas adotam a terra como centralidade e esse desejo é acrescido de anseios como trabalho, saúde, transporte e educação. O mesmo não ocorre em relação a esporte e lazer, vistos, muitas vezes, como secundários e praticamente imperceptíveis, uma vez que os quilombolas nem sempre reconhecem que a implementação de uma política pode trazer a necessidade da outra, numa dimensão intersetorial. Esse dado é corroborado por Melo, Brêtas e Monteiro (2009, p. 44) ao afirmarem que não devemos concordar com o estabelecimento de uma hierarquia das necessidades humanas, pois "o lazer é tão importante quanto todas as outras necessidades, como também se articula com elas".

Ao escreverem sobre os desafios para a gestão das políticas públicas de lazer no Brasil, Pinto et al. (2011, p. 38) apontam limites às oportunidades de vivência do lazer e os meios de superá-los, discussão decorrente do Fórum de Gestores, realizado no $20^{\circ}$ Encontro Nacional de Recreação e Lazer (ENAREL). Os limites apontados pelos autores estão relacionados à desinformação, aos espaços e equipamentos de lazer, à cultura, à gestão e à formação. A análise do debate leva-os a concluírem, entre outros aspectos, que o lazer ocupa "lugar marginal nas decisões individuais e políticas", pois não se encontra entre as prioridades de políticas públicas. Ainda, a baixa participação dos cidadãos em atividades de lazer é justificada com a escassez de segurança, dinheiro, transporte, tempo e preconceito em relação ao tempo livre.

A imersão no cotidiano quilombola não se furtou de dinâmicas que levassem os próprios moradores à reflexão sobre suas condições e sobre os limites do esporte e lazer na comunidade. O próprio fato de os pesquisadores irem a campo para discutir esse tema e desenvolverem algumas práticas corporais junto a eles auxiliou no processo de reconhecimento do esporte e lazer como direitos aos quais também precisariam ter acesso. A reflexão sobre algumas políticas públicas implementadas em território nacional, como o Programa Segundo Tempo-PST (vinculado à Secretaria de Esporte Educacional) e o Programa Esporte e Lazer da Cidade-PELC (vinculado à Secretaria Nacional de Desenvolvimento de Esporte e de Lazer) contribuiu para que os comunitários visualizassem algumas possibilidades de implementar ações nesse âmbito ${ }^{7}$.

7-De acordo com o Ministério do Esporte, o Programa Esporte e Lazer da Cidade, iniciado em 2003, mantém núcleos com o objetivo de ampliar, democratizar e uni- 
Como observado, o cotidiano dessas comunidades traz alguns entraves que precisam ser conhecidos. Há deficiências organizacionais que dificultam avanços significativos relacionados à gestão pública, uma vez que, muitas vezes, os municípios não inserem adequadamente as comunidades quilombolas em seu planejamento político, melhorando as condições de esporte, lazer, transporte e saúde. A política pública do PST, por exemplo, implementada na comunidade quilombola do Feixo, oscila entre condições favoráveis e desfavoráveis de funcionamento, decorrente das mudanças políticas e formas de gestão que elegem prioridades distintas. Ainda, a falta de instrumento de avaliação da política pública do PST na comunidade dificulta a implementação de ações que visem à sua melhoria, o que compromete o desenvolvimento desse Programa. Torna-se necessário qualificar os gestores e aprimorar o debate, levando a reflexões sobre modos peculiares de vida, insistindo em uma ação conjunta das secretarias, prevendo a articulação e integração para que as práticas do esporte e do lazer possam alcançar seus objetivos dentro das políticas públicas inclusivas.

Partindo da realidade observada, a implementação de projetos-piloto de esporte e lazer talvez possa se constituir em ações iniciais junto a essas comunidades, reconhecendo, por meio de experiências diversas, aquilo que elas já têm e que gostariam de ter, formando lideranças comunitárias e promovendo o diálogo com diferentes setores sociais. É mister, ainda, reconhecer que as práticas corporais de esporte e lazer nessas comunidades estão relacionadas diretamente à valorização do

versalizar o acesso à prática e ao conhecimento do esporte recreativo e de lazer. O Programa Segundo Tempo, como programa estratégico do Governo Federal, também iniciado em 2003, tem por objetivo democratizar o acesso à prática e à cultura do esporte de forma a promover o desenvolvimento integral de crianças, adolescentes e jovens, como fator de formação da cidadania e melhoria da qualidade de vida, prioritariamente em áreas de vulnerabilidade social. BRASIL. Ministério do Esporte. Disponível em: http://www.esporte.gov.br. Acesso em: 15 abr. 2011. Sobre políticas públicas, conferir também LIBERATO, A.; SOARES, A. (orgs.). Políticas públicas de esporte e lazer: novos olhares. Manaus; Editora da Universidade Federal do Amazonas, 2010. Sobre esses programas e a avaliação que se tem deles, cf. STAREPRAVO, F. A. Políticas públicas de esporte e lazer no Brasil: aproximações, intersecções, rupturas e distanciamentos entre os subcampos político/burocrático e científico/acadêmico. (Tese de Doutorado em Educação Física). Universidade Federal do Paraná. Curitiba, 2011. 
ambiente em que vivem, sendo potencializadas pelos recursos naturais que otimizam essas práticas, como rios, cachoeiras e mata, assim como pelos meios de comunicação de massa que vendem seus produtos e criam desejos expressos pela cidade. Nessa perspectiva, é fundante que a estrutura das políticas reconheça a organização das comunidades e atue num sistema de co-participação, em que todos se envolvam com a materialização de ações que venham ao encontro de seus interesses, numa articulação em rede, envolvendo diferentes atores sociais (quilombolas, Estado, universidade, setor privado, ONGs e sociedade civil em geral).

Os anseios dessas comunidades vão ao encontro de alguns objetivos de políticas públicas de esporte e lazer oferecidos pelo governo federal, como o Programa Segundo Tempo (PST) e o Programa Esporte e Lazer da Cidade (PELC). Entretanto, vale ressaltar que mediante as carências e dificuldades das comunidades em vários aspectos sociais, a percepção do esporte e do lazer como direitos limita-se às interlocuções estabelecidas com os pesquisadores, com base no que o quilombo já possuía de esporte e lazer e no que poderia conquistar.

\section{Considerações finais}

O desenvolvimento da pesquisa em comunidades quilombolas no Paraná no intuito de estudar as políticas públicas relacionadas a esporte/lazer (sua efetividade e possibilidades reais de implementação e/ou aperfeiçoamento) leva-nos a concluir pela necessidade de que as comunidades sejam inseridas num conjunto de ações estatais que possam dar alicerce para que elas recomponham suas próprias estratégias de luta e reconheçam suas necessidades em termos de esporte e lazer. Em complemento, é fundamental que essas ações não estejam isoladas, mas interligadas a outras esferas que promovam melhorias no campo do trabalho, da habitação, do transporte, da saúde, da educação e segurança pública.

De modo geral, o estudo aponta para o desenvolvimento de uma única política pública de esporte e lazer desenvolvida na Comunidade do Feixo, ainda não diretamente pensada para a realidade quilombola e para a variedade de práticas corporais de esporte e lazer. Atenta, ainda, para o interesse das comunidades por políticas de esporte e lazer em interlocução com outras políticas que fomentem condições materiais e existenciais a esses grupos sociais. Daí ser necessário que os re- 
sultados da pesquisa cheguem aos interessados (quilombolas, órgãos financiadores, sociedade civil), de modo a difundir amplamente os dados obtidos, democratizando seu acesso.

Como ações estratégicas a serem desenvolvidas com a pesquisa, vale destacar: a) processo contínuo de identificação das carências em termos de políticas públicas nas comunidades de modo que ações efetivas sejam realizadas a partir delas e não a partir de interesses externos a elas; b) deflagração de melhorias da política pública de esporte e lazer existente em uma comunidade quilombola (Feixo) e implementação de novas políticas em comunidades carentes, construídas com eles e não para eles; c) avaliação da política pública de esporte e lazer na comunidade quilombola do Feixo com vistas à operacionalização de novas ações em consonância com os interesses e especificidades dos grupos sociais; d) disseminação da produção científica em meio acadêmico, setores governamentais, não-governamentais e comunidades quilombolas envolvidas, de modo que os protagonistas possam se ver como co-partícipes desse processo; e) identificação dos recursos já empregados com políticas públicas de esporte e lazer nas comunidades quilombolas; f) verificação dos possíveis investimentos a serem realizados nessas comunidades a partir das necessidades identificadas; g) realização de investimentos por órgãos públicos para o desenvolvimento do esporte e lazer; h) reconhecimento da infraestrutura disponibilizada nas comunidades e seus espaços, identificando carências e benefícios; i) descrição da realidade local com indicação de investimentos potenciais a serem otimizados pelos órgãos competentes em relação à infraestrutura para o desenvolvimento do esporte e lazer nas comunidades, em consonância com suas necessidades ambientais.

Finalizada a pesquisa, será fundamental dar sequência a políticas interventoras, as quais incluem o diálogo com setores municipais, estaduais e federais no sentido de propiciar condições adequadas de esporte e lazer junto às comunidades. A identificação e articulação de gestores, grupos de pesquisa e comunidades envolvidas torna-se uma ação necessária, assim como o contato com a Secretaria de Políticas de Promoção da Igualdade Racial - SEPPIR, com a Fundação Cultural Palmares e com o Ministério do Esporte, por meio dos programas já existentes, de modo a deflagar ações a partir do reconhecimento da realidade quilombola, escutando os moradores acerca de suas carências em relação a esporte e lazer, em interlocução com outras necessidades cotidianas. 
Sport and leisure in quilombolas communities in Paraná state: realities and pointing identifying challenges for implementation and/or improvement of public policy

\begin{abstract}
This text aims to discuss the research of sport and leisure in quilombolas communities in the State of Paraná-Brasil, identifying deficiencies and assessing the specific conditions for implementation and/ or improvement of public policies for sport and leisure, in dialogue with other social spheres. The mapping of the real quilombola in State could provide a framework for intervention actions that may be considered as a sport and leisure constitutional rights to be materialized in these locations.

Keywords: Public Policies. Sports. Leisure.

Deporte y ocio en las comunidades quilombolas en el estado del Paraná: haciendo la identificación de realidades y señalando desafios para la aplicación y/o mejoramiento de las políticas públicas
\end{abstract}

\title{
Resumen
}

Este texto trata de la investigación del deporte y el ocio en cuatro comunidades quilombolas en el Estado de Paraná-Brasil con el objetivo de identificar deficiencias y evaluar las condiciones específicas para la implementación y/o mejora de las políticas públicas para el deporte y el ocio, en diálogo con otras esferas sociales. El mapeo de la realidad quilombola puede servir como un marco para las acciones de intervención que consideren el deporte y el ocio como derechos constitucionales que deben ser materializados en esos lugares.

Palabras clave: Políticas Públicas. Deportes. Ocio.

\section{Referências}

ARRUTI, J. M. Políticas públicas para quilombo: terra, saúde e educação. In: PAULA, M; HERINGER, R. Caminhos convergentes: Estado e sociedade na superação das desigualdades raciais no Brasil. Rio de Janeiro: Fundação Heinrich Boll Stiftung; Actionaid, 2009, p.75110 .

BRASIL. Constituição da República Federativa do Brasil. Brasília, 5 out. 1988. Disponível em: http://www.senado.gov.br/sf/legislacao/const/. Acesso em: maio 2008.

BRASIL. Ministério do Esporte. Disponível em: <http://www.esporte.gov.br.> Acesso em: 15 abr. 2011.

BRASIL. Fundação Cultural Palmares. Disponível em:<www.palmares.gov.br> Acesso em: 11 set. 2011. 
CAROLINA, A. Implicante. Letra de Música. Disponível em: $<$ http://ana-carolina.musicas.mus.br/letras/74517> Acesso em: 25 nov. 2011.

LIBERATO, A.; SOARES, A. (orgs.). Políticas públicas de esporte e lazer: novos olhares. Manaus: Editora da Universidade Federal do Amazonas, 2010.

MELO, V. A. de; BRÊTAS, Â.; MONTEIRO, M. B. Fundamentos do lazer e da animação cultural. In: OLIVEIRA, A. A. B. de, PERIM, G. L. (orgs.). Fundamentos pedagógicos do Programa Segundo Tempo: da reflexão à prática. Maringá: Eduem, 2009, v. 1, p. 45-69.

PARANÁ. Grupo de Trabalho Clóvis Moura. Disponível em: $<$ http://www.quilombos.pr.gov.br> Acesso em: 11 set. 2011.

PINTO, L. M. S. M. et al. Desafios para a gestão das políticas públicas de lazer no Brasil. In: ISAYAMA, H. F. et al. (orgs). Gestão de políticas de esporte e lazer. Belo Horizonte: Ed. UFMG, 2011. p. 2749.

SILVA, A. M.; FALCÃO, J. L.C. (orgs.) Práticas corporais em comunidades quilombolas de Goiás. Goiânia: Ed. da PUC Goiás, 2011.

SILVA, P. V. B. Prefácio. In: COSTA, L.G. (org.). História e cultura afro-brasileira: subsídios para a prática da educação sobre relações etnorraciais. Maringá: Eduem, 2010.

STAREPRAVO, F. A. Políticas públicas de esporte e lazer no Brasil: aproximações, intersecções, rupturas e distanciamentos entre os subcampos político/burocrático e científico/acadêmico. (Tese de Doutorado em Educação Física). Universidade Federal do Paraná. Curitiba, 2011.

Recebido em: 13/10/2011

Revisado em: 09/11/2011

Aprovado em: 17/01/2012

Endereço para correspondência

laramlara@hotmail.com

Larissa Michelle Lara 
Universidade Estadual de Maringá

Av. Colombo, 5.790

Jd. Universitário

Maringá - Paraná - Brasil

CEP 87020-900 